BLS 32, No 1 2006. DOI: http://dx.doi.org/10.3765/bls.v32i1.3481 (published by the Berkeley Linguistics Society and the Linguistic Society of America)

\title{
Deskewing the Searlean Picture: A New Speech Act Ontology for Linguistics
}

\author{
DIETMAR ZAEFFERER \\ Ludwig-Maximilians-University, Munich
}

\section{Introduction}

The overall aim of this paper is to present a speech act ontology that is motivated by general assumptions about the nature of human language and implicational universals about the grammatical coding of illocutionary force (sentence mood markers). In particular, I want to show five things: first, that the Searlean picture is skewed in that it misrepresents universally attested distinctions, overemphasizes non-universal aspects of human language, and misses important generalizations; second, that a linguistically more fruitful picture can be developed on the basis of implicational universals that constrain the range of possible codings of sentence mood and other modalities; third, that this linguistic picture can be grounded on very few elementary and universally valid assumptions about the nature of human language and its functions; fourth, that this grammatically motivated reconstruction helps in analyzing intricate syntactic patterns that interrelate German clause types; and finally, that the Searlean picture can be embedded in the linguistic picture in such a way that nothing gets lost in the deskewing process that merits preservation.

\section{A Classification of Illocutions:}

\section{John Searle's Proposal of a Philosophical Picture}

More than 30 years ago, Searle (1975) proposed a classification (initially called a taxonomy) of basic illocutions with five major categories and two subcategories which, slightly rearranged and represented in tree format, looks as follows:

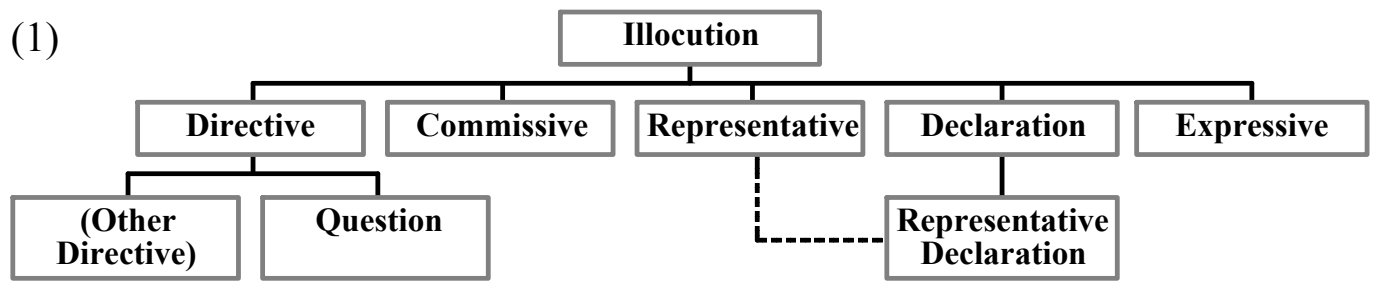




\section{Dietmar Zaefferer}

The aim was to come up with a systematic picture of the most basic categories of illocutionary acts, i.e. of those types all other types would be subtypes of. ${ }^{1}$

\subsection{How Systematic is the Searlean Picture?}

At its time Searle's proposal constituted a tremendous step forward towards a principled terminology in speech act theory. It replaced the rather poorly defined classification outlined in the last lecture of Austin's How to Do Things with Words (Austin 1955) with a much more systematic account based on a decomposition of the notion of illocutionary force into its main factors. Searle found out that "there are (at least) twelve dimensions of variation in which illocutionary acts differ from one another" (1975:345): 1) point or purpose, 2) direction of fit, 3) expressed psychological state, 4) strength of the point, 5) status of participants, 6) relations to interests of participants, 7) relations to rest of discourse, 8) propositional content, 9) non-linguistic performability, 10) dependence on extra-linguistic institution, 11) possibility of performative use of describing verb, and 12) style. Although the resulting classification ${ }^{2}$ pictured above and based mainly on the first three of these factors certainly represents a major improvement over its predecessor, upon closer scrutiny this account turns out to be less systematic than it looks.

\subsection{Main Shortcomings of the Searlean Picture}

There are at least nine respects in which Searle's proposal seems to be unsatisfactory. First, the top criterion point or purpose is ill-defined: there are always many purposes associated with an action, and even after narrowing down primary purposes the question remains open how these are to be identified. Second, the definitional value of both point and expressed psychological state is virtually eliminated at least with Representatives, whose point is to commit the speaker to the truth of the expressed proposition and whose expressed state is belief, by the claim that both are dimensions and that the "degree of belief and commitment may approach or even reach zero..." (Searle 1975:355). How can a belief or commitment with degree zero be identified? This leaves the words-toworld direction of fit as the only reliable definitional criterion. Similar problems arise with Directives and Commissives. Third, direction of fit is problematic itself, at least in its usual characterization (cf. Sobel and Copp 2001). Fourth, the classification is not a partition: its categories are neither pair-wise disjoint nor jointly exhaustive. Fifth, it disregards implicational universals of sentence mood, which is by definition that part of clause typing that indicates illocutionary force. Sixth, it destroys the integrity of the questions by subsuming them under the Directives: although canonical questions may be special cases of Directives, not all questions are. Seventh, it attributes a role and weight to Commissives, Declara-

\footnotetext{
${ }^{1}$ The dotted line between Representative and Representative Declaration indicates that the latter is a subcategory not only of Declaration, but in a way, also of Representative.

${ }^{2}$ There have been two changes from the first publication to the second (and later ones): in the title, Taxonomy was replaced by Classification, and in the text Representatives was substituted by Assertives.
} 
tions, and Expressives that is poorly motivated. Eighth, it is incomplete in that it leaves no room for exclamations. Finally, quinary branching in a classification is always a good reason for double-checking if there are no possible higher distinctions that have been overlooked.

\section{A Taxonomy of Illocutions:}

\section{The Grammar-Based Approach to a Linguistic Picture}

Figures (2) and (3) show the new picture to be discussed below (the sub-tree dominated by the Structured Epistemic Telic node has been exported for display reasons). Those nodes in the figures that correspond to nodes in figure (1) are labeled in italics.
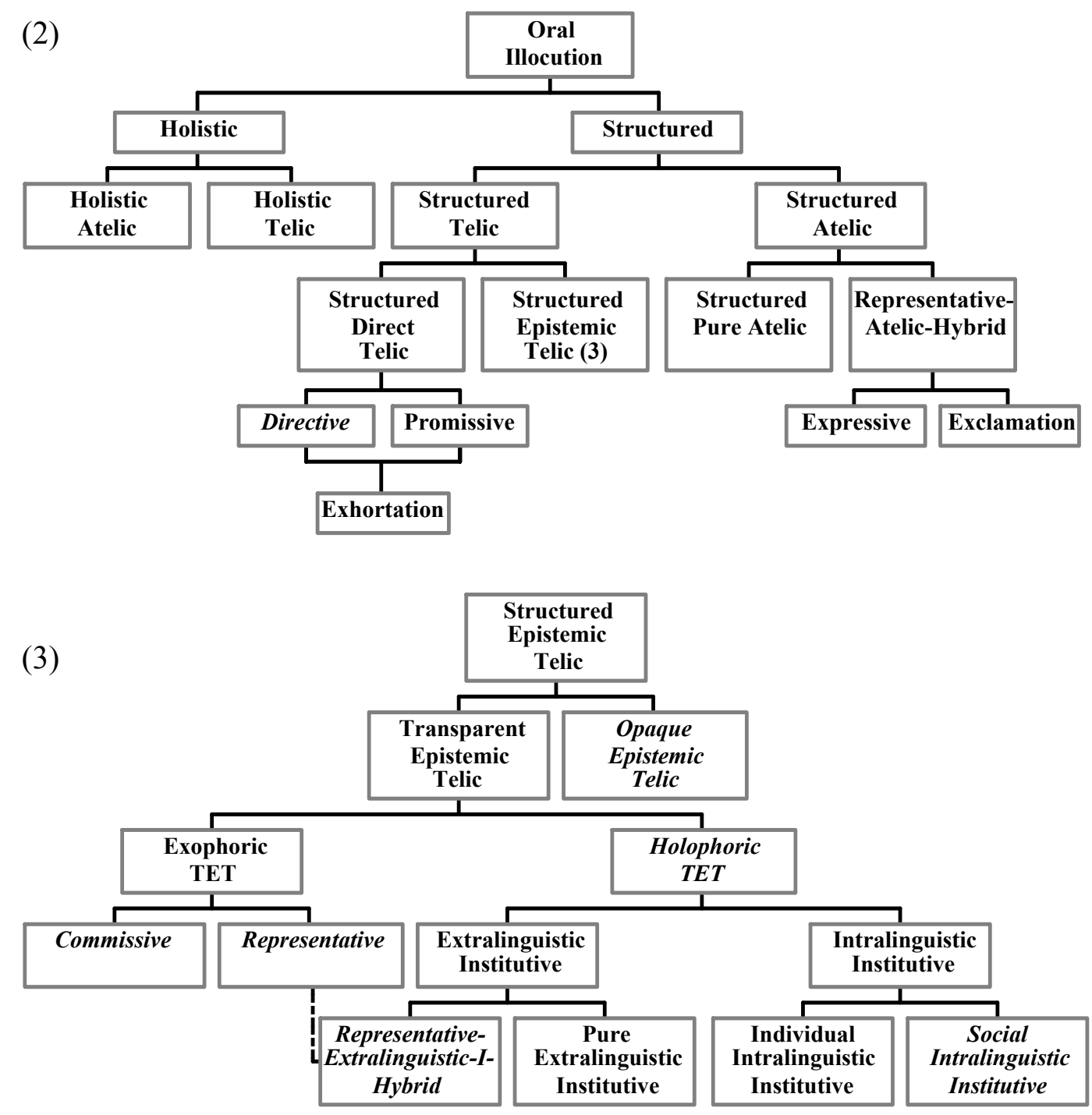
One motivation for the new taxonomy, which is an enriched and considerably improved successor to the one proposed in Zaefferer (2001), comes from hypotheses about implicational universals of sentence mood marking (cf. Hengeveld et al. 2007, König and Siemund 2007, Pak et al. 2005). Each branching of this tree corresponds to both a classification criterion and an assumed universal. Starting from the root, the most relevant criteria and universals $(U)$ are:

(A) Structure: presence of an overt distinction between sentence mood meaning and propositional content. An oral illocution is structured if its form reflects the force-content distinction, and holistic otherwise. U: if a language has structured illocutions, then it has holistic illocutions as well.

(B) Telicity: presence of a volitional attitude aiming at a specific stage transition. An oral illocution is telic if its sentence mood meaning expresses such an attitude, and atelic otherwise. U: if a language has telic illocutions, then it has atelic illocutions as well. (Atelic holistics are interjections like Wow!, telic holistics interjections like Hist!)

(C) Epistemicity: presence of an epistemic attitude layer between the volition and the propositional content. A telic illocution is epistemic if its expressed volition aims at such an attitude towards the content, and direct if it aims at the content itself. $U$ : if a language has epistemic illocutions, then it has direct illocutions as well.

(D) Promissivity: presence of a direct volitional attitude towards propositional content that exclusively characterizes a course of action of the agent. A direct telic illocution is promissive if its expressed volition aims at such content, it is directive if its expressed volition aims at content that exclusively characterizes a course of action of the addressee, and it is exhortative if its expressed volition aims at content that characterizes a joint course of action of the agent and the addressee. U: if a language has promissive illocutions, then it has exhortative illocutions, and if it has exhortative illocutions, then it has directive illocutions as well.

(E) Opacity: property of a characterization of an epistemic attitude that specifies only the dimension of variation of its content. An epistemic telic illocution is opaque if its expressed volition aims at such partially specified propositional content; it is transparent if its expressed volition aims at fully specified content. U: if a language has opaque epistemic telic illocutions, then it has transparent epistemic telic illocutions as well.

(F) Holophoricity: property of the propositional content of a given illocution that is present exactly if this content refers to the whole illocution it is part of. An epistemic telic illocution is holophoric if its expressed volition aims at an epistemic attitude towards propositional content that refers to the whole embedding illocution, else it is exophoric. U: if a language has holophoric epistemic telic illocutions, then it has exophoric epistemic telic illocutions as well. 
Note that telic and epistemic illocutions involve the presence of modal operators, which by definition come in pairs of dual counterparts. The strong telic modal is volition, and its weak counterpart is toleration (absence of preventing volition); the strong epistemic modal is knowledge, and its weak counterpart is non-exclusion (absence of excluding knowledge). Interestingly, only the strong epistemic attitude can be characterized both transparently and opaquely; the weak epistemic attitude allows only for transparent characterization.

\section{An Ontology of Illocutions: Grounding the Linguistic Picture}

\subsection{Basic Hypotheses about Human Language and Its Core Functions}

To turn a hierarchy of categories or taxonomy into an ontology, it is necessary to embed its definitions in a coherent account of the whole domain. Here is a rough outline of such a conceptualization. To begin with, it seems safe to assume that there are three elementary kinds of language use that can be characterized roughly as follows ( $l$-association means here some language-specific association relation that is based both on convention and intention):

(A) covert active language use, which consists in unperceivable pre-motor activity that triggers $l$-associated mental events;

(B) overt active language use, which consists in perceivable motor activity that makes $l$-associated mental events inferable; and

(C) receptive language use, which consists in perception of motor activity and inference of $l$-associated mental events.

This derives the following two core functions of language use:

(i) mind activating and structuring with (A) and (B) above; and

(ii) mind sharing, i.e. co-activating and co-structuring, with (B) and (C).

Assuming that there are four major kinds of mind sharing (cf. Zaefferer 2007), namely (a) attention sharing, (b) emotion sharing, (c) goal sharing, and

(d) knowledge sharing, we get some support for the linguistic picture of section 2: whereas type (a) is relevant for all illocutions in that it introduces shared topics, type (b) is relevant mainly for atelic illocutions, type (c) is relevant for telic illocutions, and type (d) is relevant for epistemic illocutions.

\subsection{A Cognitively Viable Concept of Propositional Contents \\ 3.2.1. Cognitivized Austinian Propositional Contents}

A considerable part of the inspiration for the new picture came from the observation that there is much more interaction between kinds of propositional content and illocutionary forces than is generally assumed. To cash in on that insight it proved helpful to replace the usual possible-world modeling of propositions by something capable of doing a better job in guiding analytic intuition. Based on ideas from Austin (1950) and Barwise and Etchemendy (1987), I have developed the notion of cognitivized Austinian propositional content, or CAP for short (cf. Zaefferer 2006). 
Formally, a CAP is an ordered pair $<s, T>$, where $s$ is a mentally represented situation token and $T$ is a mentally represented situation type. An applied CAP, or ACAP for short, is an ordered pair $\langle t, p>$, where $t$ is a situation token and $p$ is a CAP. If $P$ with $P:=<t,<s, T>>$ is an ACAP, we call $t$ the topic of $P, s$ the token of $P$, and $T$ the type of $P$.

\subsubsection{Reconciling Categoriality and Gradience of Truth via Decomposition}

The structure of ACAPs permits a decomposition of the venerable notion of truth into an internal and an interface component. Internally, we call an ACAP congruent if its token is of its type, and incongruent otherwise. Congruence is categorical and models the intuition that in a congruent ACAP, the type is true of the corresponding token. Concerning the interior-exterior interface, we call an ACAP 'matching' to the degree its token corresponds to its topic and 'mismatching' in the absence of such a correspondence. Thus, match is gradient and models the intuition that in a matching ACAP the token is more or less true to the corresponding topic (for the true to-true of distinction, cf. Austin 1950).

\subsubsection{A Little Typology of Propositional Contents}

Now we are in a position to distinguish between different kinds of propositional contents. We stipulate that a blueprint proposition is congruent by definition (it is a definition of a goal). It can be felicitiously used in a direct telic if its applications are mismatching in all alternative continuations, i.e. without the telic being performed. It has been successfully used in a direct telic to the degree its token matches the topic of its application in the real world. This is why direct telics are not said to be true, but rather more or less well realized.

In contrast, a picture proposition can be congruent or incongruent. It can be used only in a transparent epistemic and can be evaluated in two ways: either it is assumed to be congruent and then the degree of match of the corresponding application can be stated, or its application is assumed to match to a given degree and then congruence can be checked.

Finally, a near-proposition is defined as having an empty token; therefore, the question of congruence does not arise. It can be felicitously used as top propositions only in an opaque epistemic. Note that once a near-proposition is applied by building a token that more or less matches the topic, it becomes a congruent or incongruent picture proposition, if possibly open parameters in its type are fixed.

\subsection{A Fresh Look at Directions of Fit}

For the new picture, the following four kinds of direction of fit have proved more helpful than Searle's two (or four, including the double and the empty case): MRmatch (mind-to-reality) occurs in perception and the formation of sufficiently matching applied picture propositions; RM-match (reality-to-mind) in intentional action, including the more or less true realization of blueprint propositions; MMmatch (mind-to-mind) in all kinds of mind sharing, including the trustful interpre- 
tation of picture propositions; and RR-match (reality-to-reality) in replication, including the imitation of perceivable activities.

\subsection{Outline of a Sentence Mood-Based Ontology of Illocutionary Acts}

Using the tools developed so far, the following definitions of sentence mood meanings or basic illocutionary forces can be devised:

(Dec) The meaning of the declarative sentence mood is the transparent epistemic telic structured illocution type. In uttering a declarative sentence with propositional content $p$ (a picture proposition), the agent entitles the observer to infer that in doing so he aims at activated knowledge of $p$. In ideal communication this has the effect that the involved agents add $p$ to the shared knowledge.

(Int) The meaning of the interrogative sentence mood is the opaque epistemic telic structured illocution type. In uttering an interrogative sentence with propositional content $p$ (a near-proposition), the agent entitles the observer to infer that in doing so he aims at activated knowledge of $p$. In ideal communication this has the effect that the addressee turns $p$ into a sufficiently matching congruent applied proposition and contributes the result to the shared knowledge.

(Imp) The meaning of the imperative sentence mood is the direct telic structured illocution type. In uttering an imperative sentence with propositional content $p$ (a blueprint proposition), the agent entitles the observer to infer that in doing so he aims at a realization of $p$ by the addressee. In ideal communication this has the effect that the addressee adds $p$ to the shared goals.

(Exc) The meaning of the exclamative sentence mood is a hybrid that consists in part of the transparent epistemic telic structured illocution type and in part of the atelic structured illocution type. In uttering an exclamative sentence with propositional content $p$ (a picture proposition), the respective agent makes it inferable that her aim is (a) activated knowledge of $p$, and (b) emotional expression of the unusually high degree to which $p$ holds. In ideal communication this has the effect that the agents add $p$ to the shared knowledge and the corresponding emotion to the shared emotions.

\section{Testing the New Picture with Some Quirky German Clause Types \\ 4.1. Canonical and Less Canonical German Clause Types \\ 4.1.1. Canonical Clauses}

German root clauses, which by definition possess illocutionary force potential, are canonically verb-initial (verb-first (4) or verb-second (5)), whereas embedded clauses, which lack force, are canonically verb-final (6)-(7).

(4) Fliegt Peter nach Rom?

(5) Peter fliegt nach Rom.
'Flies Peter to Rome?'

'Peter flies to Rome.' 
(6) [Maria weiß, ] ob Peter nach Rom fliegt. '[Maria knows] if Peter to Rome flies.'

(7) [Maria weiß,] dass Peter nach Rom fliegt. '[Maria knows] that Peter to Rome flies.'

\subsubsection{Non-Canonical Clauses}

But there are also, more peripherally, verb-final root (8)-(10) and verb-initial embedded clauses (11) (PART glosses an emphatic particle):

(8) Ob Peter nach Rom fliegt?

(9) Dass Peter nach Rom fliegt!

(10) Dass du ja nach Rom fliegst!

(11) [Ich hoffe,] Peter fliegt nach Rom.
'If Peter to Rome flies?'

'That Peter to Rome flies!'

'That you PART to Rome fly!'

'[I hope] Peter flies to Rome.'

\subsection{Explaining the Properties of Non-Canonical Clause Types}

4.2.1. Gain of Force through Insubordination: Verb-Final Root Clauses

Truckenbrodt (2006) aims at a uniform explanation based on the absence of finite morphology in $\mathrm{C}$, but he admits that exclamative uses are outside the scope of his approach. Given the functional heterogeneity - (8) raises the question without expecting an answer, (9) expresses amazement, (10) insists on the compliance with an order, and there are some more - an alternative seems preferable:

(O) Orphan theory of verb-final root clauses

(O) claims that verb-final root clauses still show the effect of different matrix clauses with speaker subjects which are gone forever - not hidden by ellipsis, but roughly recoverable as expressing wondering, amazement, and insistence, respectively (other attitudes are possible) - and which determine, together with the type of the content (near-proposition (8), picture propositions (9), blueprint proposition (10)), the different non-canonical forces of these clauses. Thus, (O) is able to account for the functional heterogeneity of verb-final root clauses.

\subsubsection{Loss of Force through Subordination: Verb-Initial Dependent Clauses}

Whereas all V2-clause embedding matrices also embed VL-clauses (cf. (11) and (12)), the inverse does not hold (cf. (13) and (14)), and worse, modified V2embedders may lose this ability (cf. (15)):

$\begin{array}{lll}\text { (12) Ich hoffe, dass Peter nach Rom fliegt. } & \text { 'I hope that Peter to Rome flies.' } \\ \text { (13) Ich bezweifle, dass Peter nach Rom fliegt. } & \text { 'I doubt that Peter to Rome flies.' } \\ \text { (14) } & \text { *Ich bezweifle, Peter fliegt nach Rom. } & \text { 'I doubt Peter flies to Rome.' } \\ \text { (15) } & \text { *Ich hoffe nicht, Peter fliegt nach Rom. } & \text { 'I do not hope Peter flies to Rome.' }\end{array}$

I think that Truckenbrodt (2006) is on the right track in trying to explain the embeddability restrictions on V2-clauses by force effects: whereas canonical subordinates suffer complete loss of force, non-canonical subordinates keep at least some of their force and this imposes constraints on the embedders. Gärtner's proto-force absorption hypothesis says that V2-clauses come with an assertive 
proto-force, which in the absence of an embedder turns into a full force, whereas in the presence of an embedder it has to be absorbed (entailed) by it. The problem with the approach is that it is unclear what an assertive proto-force is and how, for instance, an epistemic attitude can be entailed, e.g. by hope.

The picture outlined above suggests a more satsifying account:

(W) Weak epistemic layer theory of embedded V2-clauses

(W) says that in embedded V2-clauses, (a) only the epistemic layer of the transparent epistemic telic force remains, and (b) the epistemic attitude is only a weak one (lack of excluding knowledge, or 'nexclusion' for short). Hoping $p$ entails nexcluding $p$; therefore, (11) is ok. Not hoping or doubting $p$ does not entail nexcluding $p$ (although it may implicate it); therefore, (14) and (15) are out. Note that neither $(\mathrm{O})$ nor $(\mathrm{W})$ would be derivable from the old picture.

\section{Relating the New Picture to the Old One}

Looking back, we are now in a position to determine the reason for the skew in the old picture that has been removed in the new one. The undeniable merits of Searle's picture come from the fact that it is a fairly adequate picture of the major illocutionary acts, at least for a prototypical Western culture where commitments and obligations play a central role. But major illocutionary acts and basic illocutionary acts are not the same, and if we compare the two pictures it seems reasonable to assume that the major skewing factor is what Barwise and Perry (1983:38) have called the fallacy of misplaced information. This will become clear in the following section where the definitions of the nodes in (1) will be compared with those of their (italicized) counterparts in (2) and (3).

First, let us have a look at Directives. According to Searle, an illocution with propositional content $p$ is a Directive if it is an attempt with the degree of strength $x$ by the agent to get the addressee to realize $p$. According to the new picture, a Directive is a structured direct telic with propositional content that characterizes exclusively an action of the addressee. This is in line with data like those from Korean that show that in this language, promissive, exhortative, and directive speech acts can be coded by sentences that differ minimally in the choice of the sentence-final particle (- $m a,-c a$, or -la, respectively) and the person features of their subjects, and which apart from that constitute a single clause type (Pak et al. 2005). If we take this formal commonality seriously, then we should see it as an indicator for a functional common denominator. This is obvious in the new picture (a volitional attitude with goals that differ only in who controls their attainability), but it is hard to see how it could be developed from the old one. ${ }^{3}$

\footnotetext{
${ }^{3}$ The obvious inadequacy of analyzing promises as requests to oneself, i.e. attempts to get oneself to do something, caused Searle to reject this idea (1975:356).
} 


\title{
Dietmar Zaefferer
}

The terms in which Searle couches his criticism of the new definition show that he does not sufficiently appreciate the significant distinction between volition and desire:

\begin{abstract}
The utterance "Come" does more than just express a desire that the hearer come, as is shown by the fact that she [the speaker] might consistently say "Of course, Max, I want you to come, but I am not actually asking or requesting you to come". If his account were right it would be impossible to express such a desire without thereby issuing a directive, but there are lots of examples to show that this is wrong. (Searle 2001:289)
\end{abstract}

I think his argument goes through, but it relies crucially on the fact that wanting is underspecified with respect to the abovementioned distinction and therefore can be used to express also mere desire. So his example cuts just the other way around: it assumes that the speaker could not consistently say Of course, Max, I said to you 'Come' and I meant it, but I was not actually asking or requesting you to come. The new definition explains this inconsistency by saying that an unmarked utterance of an imperative expresses a volitional attitude towards the content. Given that volition, in contrast to desire, entails reachability of its target with the available means, it will be hard for Max to argue $O K$, she has expressed that she aims at my coming and assumes that to be within her reach, but that does not mean she is trying to get me to come.

Next, let us compare the definitions of the Representatives. According to Searle's definition, the point of a Representative is to commit its speaker with the degree of strength $x$ to the truth of the propositional content, whereas the new picture entails that whoever performs a Representative licenses the inference that he aims at activated knowledge of the propositional content. Since the intended possessor of this knowledge is not specified, this entails a nice account of an example that Searle rightly produced as an argument against an earlier version of the new picture: it is consistent to say I don't care whether you assume that it is raining, all the same it's raining (Searle 2001:288). This is at odds with the earlier version (Zaefferer 2001) which analyzed Representatives as aiming at the assumption of the content by the addressee, but not with the current version, which entails that, given that the intended possessor of the knowledge cannot be the addressee, it must rather be the speaker himself, and which secondarily invites the inference that the addressee is intended to infer this (Whether or not you accept it, I know it).

Searle's analysis of Representatives as commitments to the truth of their content provides an especially clear illustration of the fallacy of misplaced information: commitments result from the agent's responsibility for the possible consequences of an action, be it linguistic or something else. When the air traffic controller utters The runway is clear, he is strongly committed to the truth of what he says because he could cause the death of hundreds of people, and when the shop customer replies I am fine to the cashier's routine question, she is not committed at all to the truth of this Representative, although she licenses the inference 
that she aims at activated knowledge that she is doing fine, but in view of the pertinent social conventions this knowledge is easily devaluated.

The label Declaration from the old picture has been replaced by holophoric transparent epistemic telic (holophoric TET for short) in the new one, and again this indicates a reconceptualization. Although Searle's defining characteristic of this class, "that the successful performance of one of its members brings about the correspondence between the propositional content and reality" (1975:358), has been adopted, both his assumption of a double direction of fit and his claim that a successful performance results in "some alternation in the status or condition of the referred to object or objects" (1975:358) are rejected. The propositional content of a holophoric TET is congruent by definition, and in case of a successful performance, it is matching as well. In that case, there is also a mind-to-mind fit, which explains why the relevant reality can only be social or individual institutional reality. Cases like This is a reminder that the use of cell phones is not permitted on our flights are problematic for Searle's claim because it is not clear what the change of state of the referent could be, but they are not so for the new picture.

Another shortcoming of the old picture is the non-disjointness of its categories. An especially clear case is what Searle calls Expressives, speech acts characterizable in English by verbs like thank, congratulate, apologize, condole, deplore, and welcome. The purpose of Expressives is "to express the psychological state specified in the sincerity condition about a state of affairs specified in the propositional content" (Searle 1975:356). The examples show that this is quite misleading: although the propositional content of I apologize for stepping on your toe includes a specification of the state of affairs the relevant attitude is about (that I stepped on your toe), the complete content rather characterizes what the agent is doing in making his utterance. Since the propositional content refers to the whole act it is a proper part of, this is a clear case of a holophoric transparent epistemic telic, i.e. an illocution that aims at activated knowledge of the proposition that the agent apologizes for stepping on the addressee's toe, which is congruent by definition, and which is matching exactly if the apology is performed. Given that apologies are an intralinguistic social institution, they illustrate the reallocation of Searle's Expressives to the rightmost node at the bottom of (3). This concludes the comparison of selected nodes of the two pictures.

I hope to have shown that the skew of the Searlean picture results from his failure to distinguish between basic illocutionary force as expressed by sentence mood and canonical illocutionary force as expressed by the given mood in default situations. Consequently, a deskewed picture can be obtained by assuming rather lean sentence mood meanings that can easily be strengthened in default situations to yield canonical forces, but which also serve to account for other forces in virtue of their compatibility with different, non-default situations. 


\section{Dietmar Zaefferer}

\section{References}

Austin, John L. 1950. Truth. Proc. of the Aristotelian Society. Supp. vol. xxiv. Austin, John L. 1955. How to Do Things with Words. Oxford: Clarendon Press. Barwise, Jon, and John Etchemendy. 1987. The Liar: An Essay in Truth and Circularity. Oxford: Oxford University Press.

Barwise, Jon, and John Perry. 1983. Situations and Attitudes. Cambridge, MA: MIT Press.

Hengeveld, Kees, et al. 2007. Basic Illocutions in the Native Languages of Brazil. Advances in Functional Discourse Grammar: Alfa - Revista de Lingüistica 51(2):73-90.

König, Ekkehard, and Peter Siemund. 2007. Speech Act Distinctions in Grammar. In Timothy Shopen, ed., Language Typology and Syntactic Description, Volume I: Clause Structure, 276-324. Cambridge: Cambridge University Press.

Pak, Miok, Paul Portner, and Raffaela Zanuttini. 2005. What Korean Promissives Tell Us about Jussive Clause Types. Abstracts for CSSP 2005.

Searle, John R. 1975. A Taxonomy of Illocutionary Acts. In Keith Gunderson, ed., Language, Mind, and Knowledge, 344-369. Minneapolis: University of Minnesota Press. [Reprinted as: A Classification of Illocutionary Acts, Language in Society 5:1-23.]

Searle, John R. 2001. Modals and Illocutionary Forces: Reply to Zaefferer. Revue Internationale de Philosophie 216 Searle - With His Replies, 286-290.

Sobel, David, and David Copp. 2005. Against Direction of Fit Accounts of Belief and Desire. Analysis 61(1):44-53.

Truckenbrodt, Hubert. 2006. On the Semantic Motivation of Syntactic Verb Movement to C in German. Theoretical Linguistics 32(3):257-306.

Zaefferer, Dietmar. 2001. Deconstructing a Classical Classification: A Typological Look at Searle's Concept of Illocution Type. Revue Internationale de Philosophie 216 Searle - With His Replies, 209-225.

Zaefferer, Dietmar. 2006. Conceptualizing Sentence Mood: Two Decades Later. In P. Brandt and E. Fuß, eds., Form, Structure, and Grammar: A Festschrift Presented to Günther Grewendorf on Occasion of His 60th Birthday, 367-382.

Zaefferer, Dietmar. 2007. Language as Mind Sharing Device: Mental and Linguistic Concepts in a General Ontology of Everyday Life. In A. Schalley and D. Zaefferer, eds., Ontolinguistics: How Ontological Status Shapes the Linguistic Coding of Concepts, 189-222. Berlin: Mouton de Gruyter.

Dietmar Zaefferer

Ludwig-Maximilians-University, Munich

Institut für Theoretische Linguistik

Schellingstr. 7

D-80799 München

zaefferer@lmu.de 